Check for updates

Cite this: RSC Adv., 2017, 7, 43266

\section{Selenium-phycocyanin from selenium-enriched cultures of Nostoc sp. isolated from rice field prevents human kidney cells from paraquat- induced damage}

\begin{abstract}
Hongzhi He, ${ }^{a}$ Saijun Liu, ${ }^{\mathrm{b}}$ Huashou Li ${ }^{\mathrm{a}}$ and Tianfeng Chen (DD *c
Selenium-containing phycocyanin (Se-PC) was purified from Se-enriched cultures of a nitrogen-fixing cyanobacterium (Nostoc sp.) using fast protein liquid chromatography. Ammonium sulfate precipitation, DEAE-Sepharose ion-exchange chromatography, and Sephacry S-300 size exclusion chromatography were employed in the process of protein purification. The purity ratio and the separation factor of the purified Se-PC were found to be 5.97 and 14.73, respectively. The Se content in the Se-PC was $550 \mu \mathrm{g} \mathrm{g}^{-1}$ protein as determined by ICP-AES analysis. Interestingly, we also found that, Se-PC could effectively suppress the paraquat $(P Q)$-induced cell death and morphological changes, reverse $P Q$-induced DNA fragmentation and nuclear condensation, and block PQ-induced cell apoptosis through inhibition of superoxide overproduction in human kidney HK-2 cells. The results indicate that $\mathrm{Se}-\mathrm{PC}$ is a promising selenium species for the protection of renal cells from paraquat-induced damage.
\end{abstract}

Received 26th July 2017

Accepted 28th August 2017

DOI: 10.1039/c7ra08250a

rsc.li/rsc-advances a large scale for biotechnological purposes, may reduce contamination risk and production costs of cultivation. ${ }^{\mathbf{1 0}}$ Indeed, as edible blue-green algae, Nostoc species including $N$. flagelliforme and $N$. commune have been used as food for thousands of years in China. ${ }^{\mathbf{1 1}}$ There have been some reports about purification of PC from nitrogen-fixing cyanobacteria. ${ }^{\mathbf{1 2 - 1 4}}$ Moreover, Sun et $a l .{ }^{15}$ recorded that phycocyanin (PC) treatment significantly attenuated PQ-induced acute lung injury in rats. At the same time, oral supplementation inorganic Se showed beneficial effects on the overall antioxidant potential of the animals because it can protect cells against the effects of free radicals. ${ }^{16}$ There are some reports that show antioxidant activity of selenium-containing phycobiliproteins purified from Se-enriched $S$. platensis. ${ }^{\mathbf{1 7 - 1 9}}$ In previous determinations, selenium-containing PC (Se-PC) purified from Se-enriched $S$. platensis showed enhanced antioxidant abilities against oxidative damage in human erythrocytes through inhibition of reactive oxygen species (ROS) generation. ${ }^{20}$ However, no information about Se-PC for PQ-induced injury treatment is available. In the current study, Se-PC was purified from a seleniumenriched diazotrophic cyanobacterium Nostoc sp., and the protective effects and mechanism of Se-PC against PQ-induced renal injury was investigated.

\section{Materials and methods}

China Agricultural University, Guangzhou 510642, China

${ }^{b}$ Department of Dermatology and Venerology, The First Affiliated Hospital of Jinan University, Guangzhou 510630, China

${ }^{c}$ Department of Chemistry, Jinan University, Room 303, Guangzhou 510632, China. E-mail: tchentf@jnu.edu.cn; Fax: +8620 85221263; Tel: +862085225962

\subsection{Materials}

The nitrogen-fixing cyanobacterium Nostoc sp. (FACHB-85) was obtained from the Freshwater Algae Culture Collection of the 
Institute of Hydrobiology, the Chinese Academy of Sciences and which was originally isolated from rice field in south China. DEAE-Sepharose was purchased from Sigma-Aldrich. The ultrapure water used in all experiments was supplied by a Milli-Q water purification system from Millipore. All the reagents used for cell culture experiments were bought from GIBCO.

\subsection{Cultivation of high Se-enriched Nostoc sp. cells}

Nostoc sp. was cultured with sterilized $\mathrm{N}$-free mineral medium BG11 at $27^{\circ} \mathrm{C}$ with a light illumination of $3000 \mathrm{~lx}$ and a light : dark cycle of $16 \mathrm{~h}: 8 \mathrm{~h}$. For the cultivation of Se-enriched Nostoc sp., a stepwise Se addition procedure was carried out based on the results of toxicological tests, where $2 \mathrm{mg} \mathrm{L}^{-1} \mathrm{Se}$ in the form of sodium selenite was added to the medium on day 7,8 , and 9, respectively. The accumulative concentration of Se was $6 \mathrm{mg} \mathrm{L}^{-1}$. On day 14, algal cells were collected by centrifuging at $10000 \mathrm{~g}$ for $10 \mathrm{~min}$ at $-4{ }^{\circ} \mathrm{C}$ and then lyophilized.

\subsection{Separation and purification of PC and Se-PC by FPLC}

The separation and purification procedure of Se-PC and PC was conducted by using the method of stepwise precipitation as we previously described. ${ }^{17,21}$ The sample was eluted with increasing $\mathrm{NaCl}$ concentration gradient. The pooled fractions were centrifuged, purified and desalted on a Sephacryl S-300 column.

\subsection{Spectroscopic determination}

A spectrophotometer method was employed to measure the UV-vis absorption spectra of testing samples. The purity ratio $\left(A_{620} / A_{280}\right)$ and the separation factor $\left(A_{620} / A_{655}\right)$ were calculated based on the UV-vis spectra.

\subsection{Measurement of total Se}

ICP-AES method was used to determine Se concentration. The sample was digested with $1 \mathrm{~mL}$ of $\mathrm{H}_{2} \mathrm{O}_{2}$ and $3 \mathrm{~mL}$ of concentrated nitric acid in a digestive stove (Qian Jian Measuring Instrument Co., Ltd., China) at $180{ }^{\circ} \mathrm{C}$ for $3 \mathrm{~h}$. The digested product was reconstituted to $10 \mathrm{~mL}$ with Milli-Q water and used for total Se determination.

\subsection{Cell culture and PQ treatment}

Human kidney (HK-2) proximal tubular cell line was purchased from American Type Culture Collection (ATCC, Manassas, VA). The cells were incubated in Dulbecco's modified Eagle's medium (DMEM), supplemented with 10\% fetal bovine serum (FBS), $100 \mathrm{U} \mathrm{mL}^{-1}$ penicillin, and $50 \mathrm{U} \mathrm{mL}^{-1}$ streptomycin in a humidified incubator with $5 \% \mathrm{CO}_{2}$ atmosphere at $37^{\circ} \mathrm{C}$. HK-2 cells were seeded at a density of $6 \times 10^{4}$ cells $\mathrm{mL}^{-1}$ and pretreated with PQ for $3 \mathrm{~h}$ before the application of Se-PC or PC. Both living and dead cells were counted under microscopy with staining by trypan blue solution.

\section{7 $\mathrm{ABTS}^{+}$free radical scavenging activities}

$\mathrm{ABTS}^{+}$free radical scavenging activities of antioxidants were measured according to the method described by Zhang and coworkers. ${ }^{17}$ Briefly, $50 \mu \mathrm{L}$ of the tested samples was mixed with
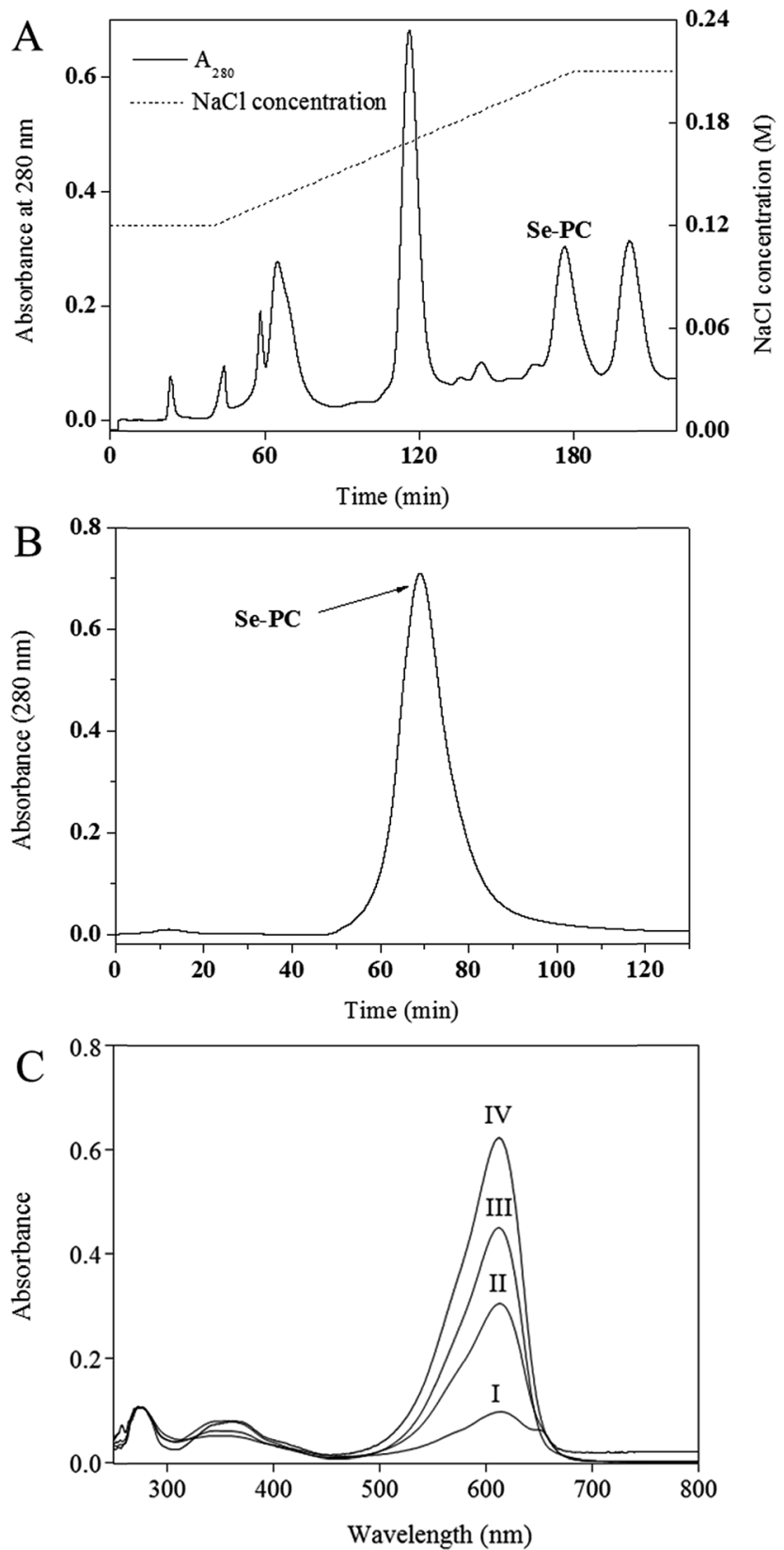

Fig. 1 (A) DEAE-Sepharose chromatography of Nostoc sp. selenium-phycocyanin (Se-PC): the sample was eluted with increasing $\mathrm{NaCl}$ concentration gradient, first at $0.12 \mathrm{M}$ for $40 \mathrm{~min}$, followed by $0.12-0.21 \mathrm{M}$ for 40 to $180 \mathrm{~min}$ and then maintained at $0.21 \mathrm{M}$ until

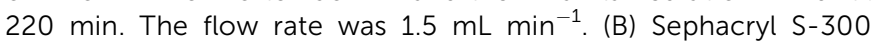
chromatography of Nostoc sp. Se-PC: the sample was eluted with $2 \mathrm{mM} \mathrm{Na}$-phosphate buffer (pH 7.0) at $1 \mathrm{~mL} \mathrm{~min}^{-1}$. (C) UV-vis spectra of Se-PC obtained in different steps of purification: (I) crude extract; (II) fraction obtained from $50 \%$ ammonium sulfate precipitation; (III) pooled fractions obtained from DEAE-Sepharose chromatography; (IV) pooled fractions obtained from Sephacryl S-300 chromatography. 
$1 \mathrm{~mL}$ of ABTS reagent with absorbance of $0.70 \pm 0.02$ at $734 \mathrm{~nm}$, and then the absorbance at $734 \mathrm{~nm}$ was measured after the initiation of mixing for $6 \mathrm{~min}$.

\subsection{Determination of caspase-3 activity}

The caspase activity of the samples was assessed by measuring the fluorescence intensity of caspase substrates with the excitation and emission wavelength at $380 \mathrm{~nm}$ and $440 \mathrm{~nm}$, respectively. ${ }^{22}$

\subsection{TUNEL assay and DAPI staining}

DNA fragmentation of HK-2 cells was detected by TUNEL assay followed the same procedure that described previously. ${ }^{22}$

\subsection{Determination of ROS generation}

The effects of PQ, Se-PC and PC on the ROS generation were assessed by using a DCFH-DA assay in HK-2 cells as described previously. ${ }^{23}$ Intracellular ROS level was quantified by measuring the fluorescence intensity of treated cells under a microplate reader (Bio-tek), with the excitation and emission wavelength at $488 \mathrm{~nm}$ and $525 \mathrm{~nm}$, respectively.

\subsection{Statistical analysis}

All results are presented as mean \pm standard deviation (SD) ( $n=$ 3). Statistical analysis was carried out by using SPSS statistical package (SPSS 13.0 for Windows; SPSS, Inc., Chicago, IL). The difference between two groups was analyzed by two-tailed Student's $t$ test. Differences with $P<0.05\left(^{*}\right)$ were considered statistically significant. The difference between three or more groups was conducted using the one-way analysis of ANOVA followed by the Student-Newman-Keuls post hoc test. Bars with different characters are statistically different at $P<0.05$.

\section{Results and discussion}

\subsection{Purification of Se-PC and PC by FPLC and measurement of Se concentration}

The results for purification of Se-PC from Se-enriched Nostoc sp. are shown in Fig. 1 and Table 1. First, a stepwise precipitation procedure using $\left(\mathrm{NH}_{4}\right)_{2} \mathrm{SO}_{4}$ at $30 \%$ and $50 \%$ saturation degree was conducted. ${ }^{20}$ Contaminating proteins were

Table 1 Purity ratio, separation factor and Se concentration of Se-PC obtained in different purification steps

\begin{tabular}{|c|c|c|c|}
\hline Purification step & $\begin{array}{l}\text { Purity ratio } \\
\left(A_{620} / A_{280}\right)\end{array}$ & $\begin{array}{l}\text { Separation factor } \\
\left(A_{620} / A_{655}\right)\end{array}$ & $\begin{array}{l}\text { Se concentration } \\
\left(\mu \mathrm{g} \mathrm{g}{ }^{-1} \text { protein }\right)\end{array}$ \\
\hline Crude extract & 0.93 & 1.69 & 243 \\
\hline $\begin{array}{l}\text { Precipitation with } \\
50 \% \text { saturation of } \\
\left(\mathrm{NH}_{4}\right)_{2} \mathrm{SO}_{4}\end{array}$ & 2.94 & 5.17 & 317 \\
\hline $\begin{array}{l}\text { DEAE-Sepharose fast } \\
\text { flow chromatography }\end{array}$ & 4.26 & 10.86 & - \\
\hline $\begin{array}{l}\text { Sephacryl S-300 } \\
\text { chromatography }\end{array}$ & 5.97 & 14.73 & 550 \\
\hline
\end{tabular}

precipitated in $\left(\mathrm{NH}_{4}\right)_{2} \mathrm{SO}_{4}$ and $\mathrm{Se}-\mathrm{PC}$ fraction was precipitated in $\left(\mathrm{NH}_{4}\right)_{2} \mathrm{SO}_{4}$ at $50 \%$ saturation. As shown in Table 1 , the stepwise precipitation enhanced the purity ratio $\left(A_{620} / A_{280}\right)$ and the separation factor $\left(A_{620} / A_{655}\right)$ of Se-PC to 2.94 and 5.17 , respectively. The peak of Se-PC appeared at about $176 \mathrm{~min}$ and a rational separation of Se-PC from other algal proteins was visualized (Fig. 1A). The purity ratio and separation factor of SePC reached 4.26 and 10.86, respectively. An effective removal of
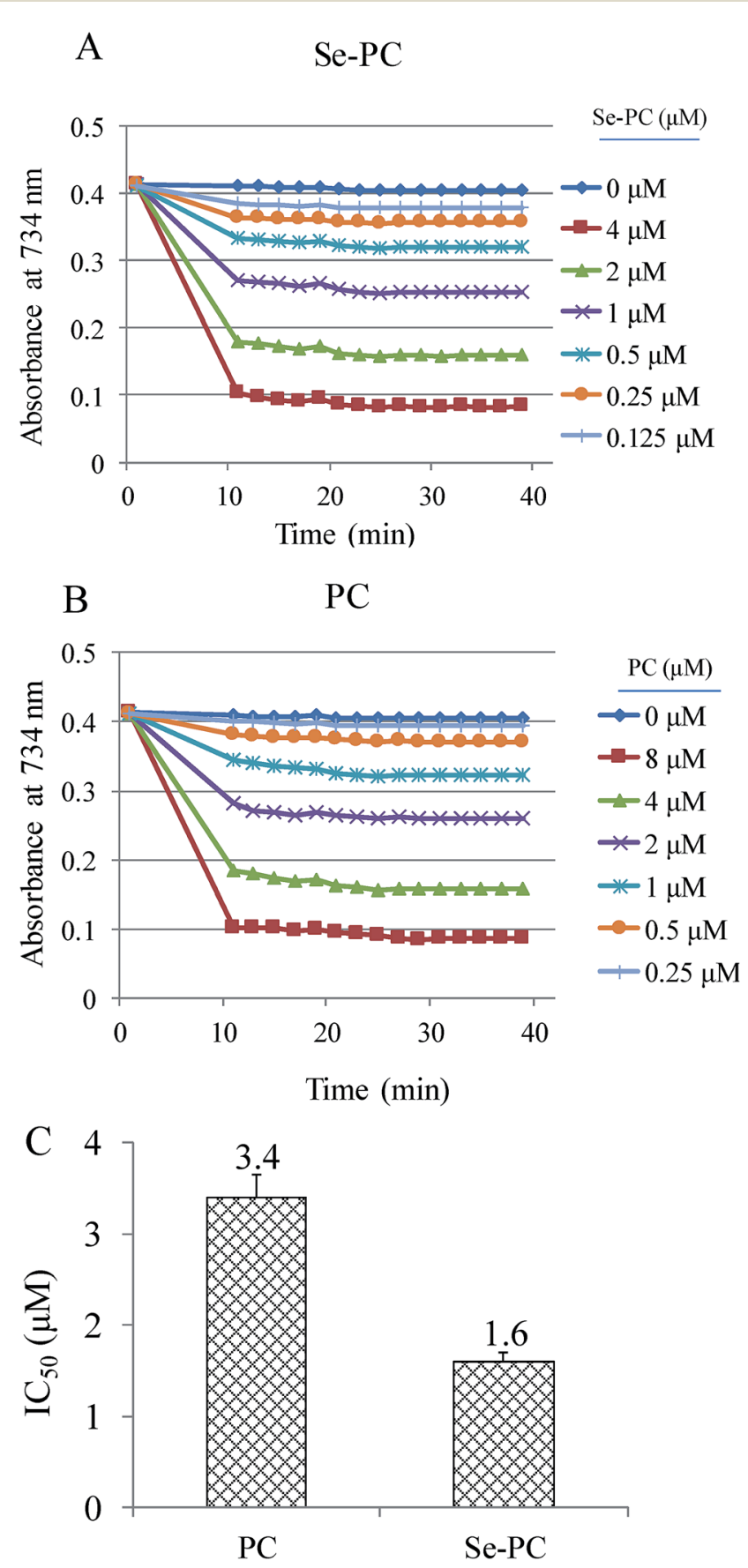

Fig. 2 (A) Antioxidant activity of selenium-phycocyanin (Se-PC) by scavenging ABTS free radicals. (B) Antioxidant activity of PC by scavenging $A B T S$ free radicals. $(C)$ The $I_{50}$ indicating the half maximal inhibitory concentration at $30 \mathrm{~min}$. 

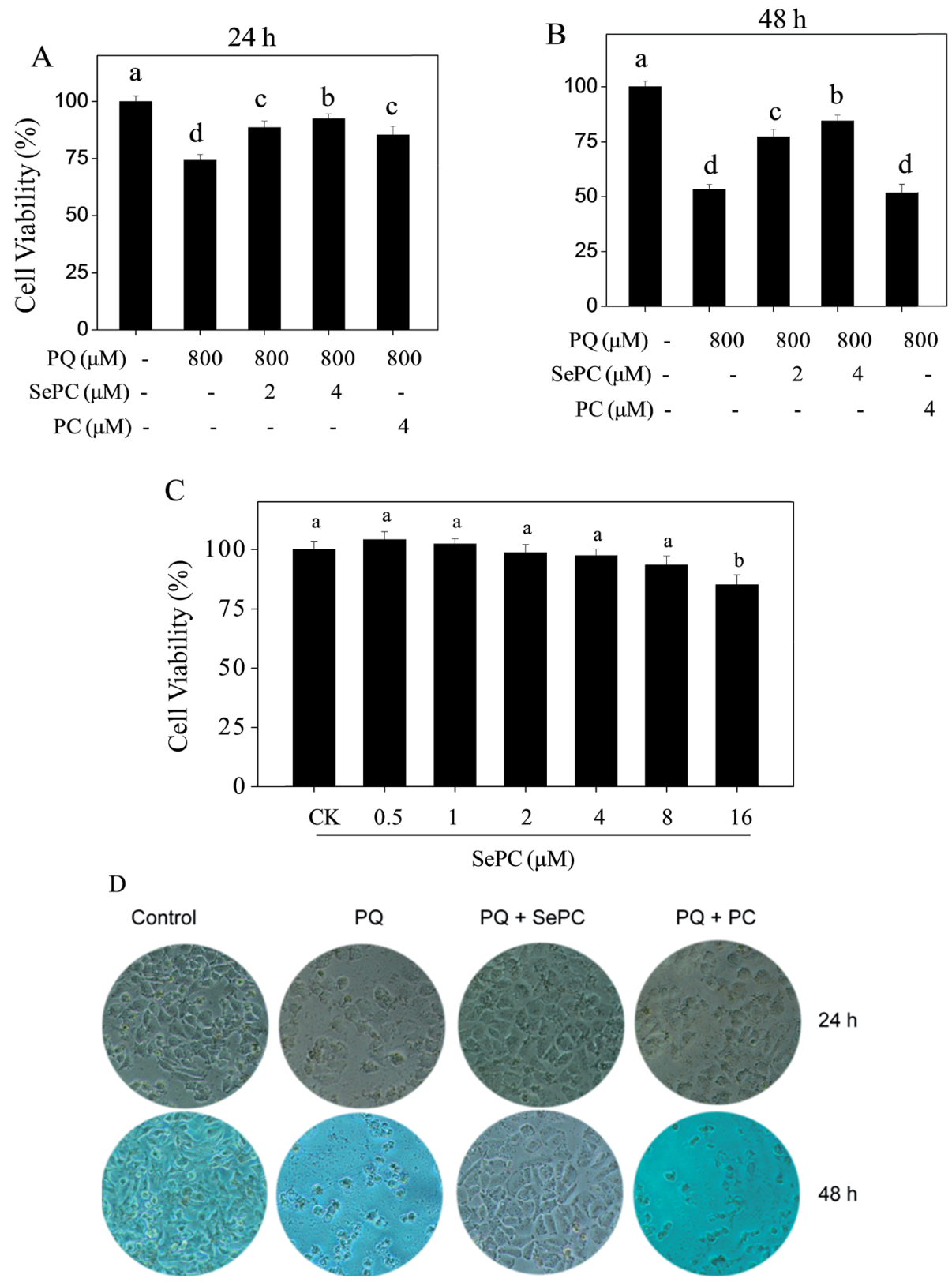

Fig. 3 (A) Effect of phycocyanin (PC) and selenium-phycocyanin ( $\mathrm{Se}-\mathrm{PC}$ ) on cell viability of HK2 cells after $24 \mathrm{~h}$ exposure to paraquat (PQ). (B) Effect of PC and Se-PC on cell viability of HK2 cells after $48 \mathrm{~h}$ exposure to PQ. (C) Effect of different concentrations of Se-PC on cell viability in $P Q$-induced HK2 cells. (D) Effect of PC and Se-PC on cell morphology of PQ-induced HK2 cells. Different letters indicate statistically significant differences $(P<0.05)$.

other algal proteins before 120 min might be the key reason for achieving the high purity ratio of Se-PC. The purity was similar to previous works also employing DEAE ion exchange chromatography for PC purification from cyanobacteria. ${ }^{24-26}$ Sephacryl S-300 size exclusion chromatography was used for further purification of Se-PC. As a result, a sharp peak of Se-PC appeared in Fig. 1B. The purity ratio and separation factor of SePC after this step were increased to 5.97 and 14.73, respectively. As compared with methods addressed by other authors, the purification method in the present study gave a higher purity of Se-PC. ${ }^{24-26}$ Se content of protein obtained in different purification steps was shown in Table 1 . After purification by ion exchange and size exclusion chromatography, Se-PC with the Se content at $550 \mu \mathrm{g} \mathrm{g}^{-1}$ was ultimately obtained. It is higher than that of Se-PC purified from $S$. platensis in our previous study. ${ }^{20}$

\subsection{Characterization of Se-PC by UV-vis}

The characteristic absorption peak at $620 \mathrm{~nm}$ and strong absorbance below $300 \mathrm{~nm}$ in the UV-vis spectra of various Se-PC fractions (shown in Fig. 1C) corroborated the presence of the Se$\mathrm{PC}$ protein. The reduced absorption intensity of peaks at $280 \mathrm{~nm}$ and $655 \mathrm{~nm}$ indicated the enhanced purity of Se-PC in terms of purity ratio $\left(A_{620} / A_{280}\right)$ and separation factor $\left(A_{620} / A_{655}\right)$ (Table 1$)$. 


\subsection{Antioxidant activity of PC and Se-PC}

$\mathrm{ABTS}^{*}$ free radical scavenging assay was used to determine the antioxidant activity of PC and Se-PC. ${ }^{21}$ In the present study, the antioxidant activity of Se-PC is represented as the inhibition percentage. As shown in Fig. 2, the suppression effect of Se-PC on ABTS oxidation was stronger than that of PC, indicating the greater antioxidant activity of Se-PC in hydrophilic environment. For instance, Se-PC shows dose-dependent inhibition of ABTS oxidation, and the $\mathrm{IC}_{50}$ (half maximal inhibitory concentration) of Se-PC $(1.60 \mu \mathrm{M})$ and PC $(3.44 \mu \mathrm{M})$ further confirmed this better antioxidant activity of Se-PC than that of PC.

\subsection{Se-PC attenuates PQ-induced nephrotoxicity in HK-2 cells}

Our previous studies have showed that selenium-containing allophycocyanin purified from selenium-enriched S. platensis showed enhanced hepatoprotective effects through reversing oxidative stress-induced cytotoxicity in HepG2 human hepatoma carcinoma cells. ${ }^{27}$ To confirm the possibility that $\mathrm{Se}$ incorporation into $\mathrm{PC}$ is able to enhance its properties in prevention of PQ-induced nephrotoxicity, MTT reduction assay was used to evaluate the possible protective effects of Se-PC on HK-2 cells. As shown in Fig. 3A and B, the treatment of HK-2 cells with PQ time-dependently decreased HK-2 cell viability. For instance, cells treated with $800 \mu \mathrm{M}$ PQ for 24 and $48 \mathrm{~h}$ decreased the cell viability by $25.7 \%$ and $46.8 \%$, respectively. However, the pretreatment with Se-PC significantly relieved this cytotoxic effect, and Se-PC exhibited better protective effect than that of PC. Pretreatment with $4 \mu \mathrm{M}$ Se-PC significantly increased the cell viability from $53.2 \%$ (PQ, $48 \mathrm{~h}$ ) to $77.3 \%$ (SePC) while with $4 \mu \mathrm{M}$ PC the cell viability did not significantly change in contrasted with PQ treatment. For instance, Se-PC treatment (less than $8 \mu \mathrm{M}$ ) showed no significant cytotoxicity toward HK-2 cells (Fig. 3C). Only with $16 \mu \mathrm{M}$ Se-PC, the viability of HK-2 cells was drastically decreased by $14.7 \%$.

In order to confirm the protective effect of Se-PC, a phasecontrast microscopy was employed to observe the cell morphological changes. As shown in Fig. 3D, the exposure of HK-2 cells to $800 \mu \mathrm{M}$ PQ for 24 and $48 \mathrm{~h}$ caused a significant drop of cell density and elimination of cell-to-cell contact. However, these changes caused by PQ treatment were significantly reversed by the combined treatment with $4 \mu \mathrm{M}$ Se-PC. In contrast, PC treatment showed worse protective effect than that of Se-PC. Based on the above results, it suggested that Se incorporation into PC enhances its ability to suppress PQcaused cytotoxicity in HK-2 cells.

\subsection{The effects of PC and Se-PC on PQ-induced apoptosis in HK-2 cells}

Induction of cell apoptosis by exotic insults is an effective way to inhibit cell proliferation. ${ }^{21,28}$ Caspase is fundamentally important for regulating cell apoptosis. ${ }^{29}$ Caspase-3 as the executor of apoptosis can inactivate PARP and initiate cell apoptosis. ${ }^{30}$ Accumulated evidences have indicated that cisplatin-induced nephrotoxicity involves activation of caspase-3 in renal tubule epithelial. $^{31}$ Therefore, our results suggest that PQ-induced cytotoxicity against HK-2 cells was achieved by induction of apoptosis, as convinced by the activation of caspase-3.

As shown in Fig. 4A, the treatment of HK-2 cells with $800 \mu \mathrm{M}$ PQ significantly activated the caspase- 3 from $100 \%$ to $194.2 \%$, indicating the existence of apoptosis in HK-2 cells. However, PQ-induced activation of caspase-3 was markedly suppressed by Se-PC co-treatment. For instance, treatment with $4 \mu \mathrm{M} \mathrm{Se}-\mathrm{PC}$ dramatically decreased the caspase-3 activity from $194.2 \%$ (PQ) to $131.1 \%$ (Se-PC). Moreover, $4 \mu \mathrm{M}$ Se-PC alone caused no change in caspase-3 activity. The results above clearly suggest that Se-PC inhibits PQ-induced apoptosis in HK-2 cells through the inactivation of caspase-3, and Se incorporation into PC enhances its ability in inhibition of PQ-induced HK-2 cell apoptosis.

Apoptotic cells may undergo nuclear condensation and DNA fragmentation. ${ }^{22}$ DNA fragmentation is a critical biochemical hallmark of apoptotic cells. TUNEL enzymatic labeling can be employed to especially detect the DNA fragmentation in early stage of apoptotic cells. ${ }^{32}$ Fig. 4B showed that $800 \mu \mathrm{M}$ PQ treatments caused evident DNA fragmentation of HK-2 cells, as
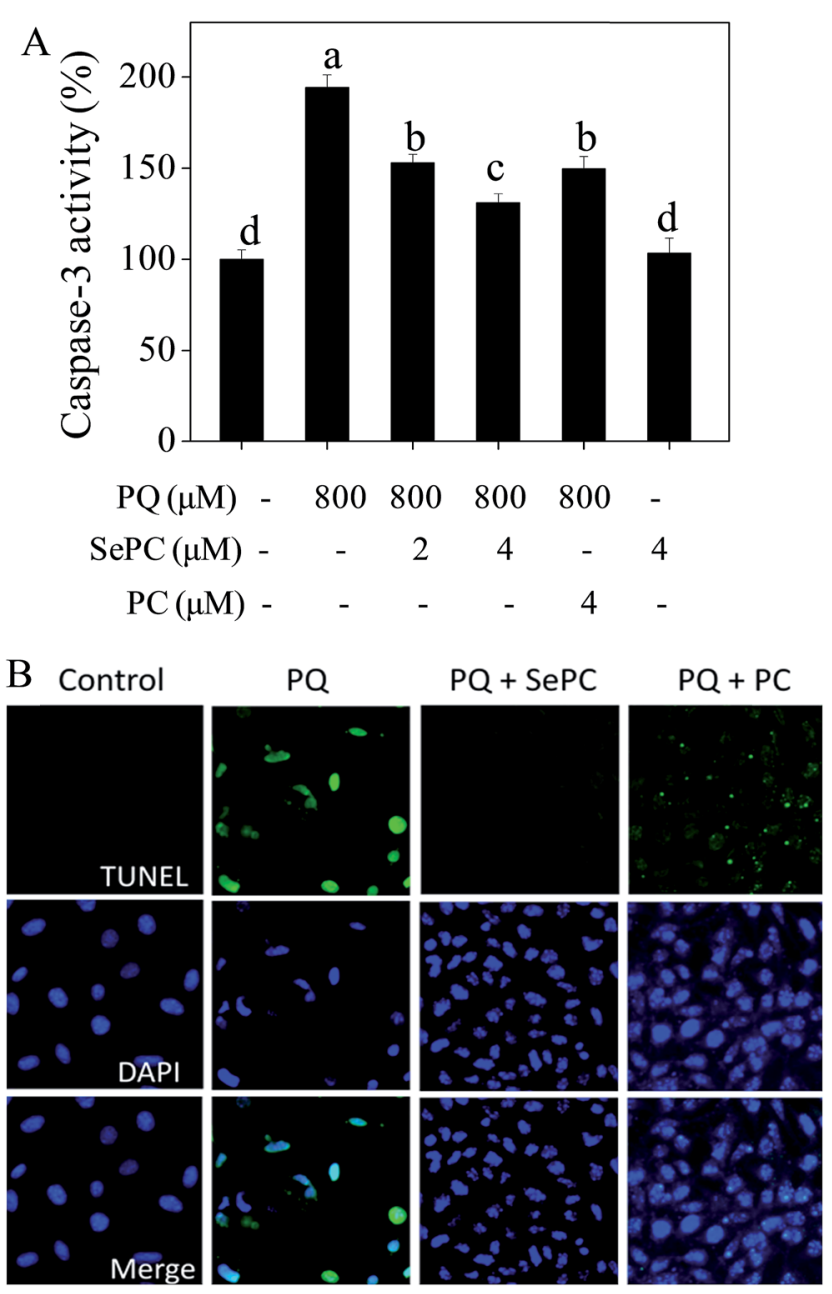

Fig. 4 (A) Selenium-phycocyanin (Se-PC) inhibits paraquat ( $P Q$ ) induced activation of caspase-3. (B) Se-PC reverses PQ-induced DNA fragmentation and nuclear condensation in $\mathrm{HK}-2$ cells. 
convinced by the bright green fluorescence. However, PQinduced DNA fragmentation was completely reversed by $\mathrm{Se}-$ PC co-treatment, as convinced by the decreased number of TUNEL-positive cells. This protective effect of Se-PC on HK-2 cells was further confirmed by DAPI staining. For instance, cells exposed to $800 \mu \mathrm{M}$ PQ exhibited typical nuclear condensation. However, Se-PC co-treatment effectively blocked PQinduced morphological alterations. Moreover, Se-PC showed better protective effect than that of PC. These results further confirmed that Se incorporation in PC reduces DNA fragmentation and nuclear condensation, which are indicators of apoptosis. These effects contribute to the general trend of preventing $\mathrm{PQ}$-induced apoptosis.

\subsection{Se-PC prevents PQ-induced superoxide overproduction in HK-2 cells}

Reactive oxygen species (ROS), including hydroxyl radical and superoxide anion, bring out severe harm to intracellular proteins, membrane lipids and DNA which ultimately results in cell apoptosis. ${ }^{22,23}$ Emerging studies have reported that ROS production is related to several types of human pathological conditions, including cisplatin-induced nephrotoxicity. ${ }^{33,34}$
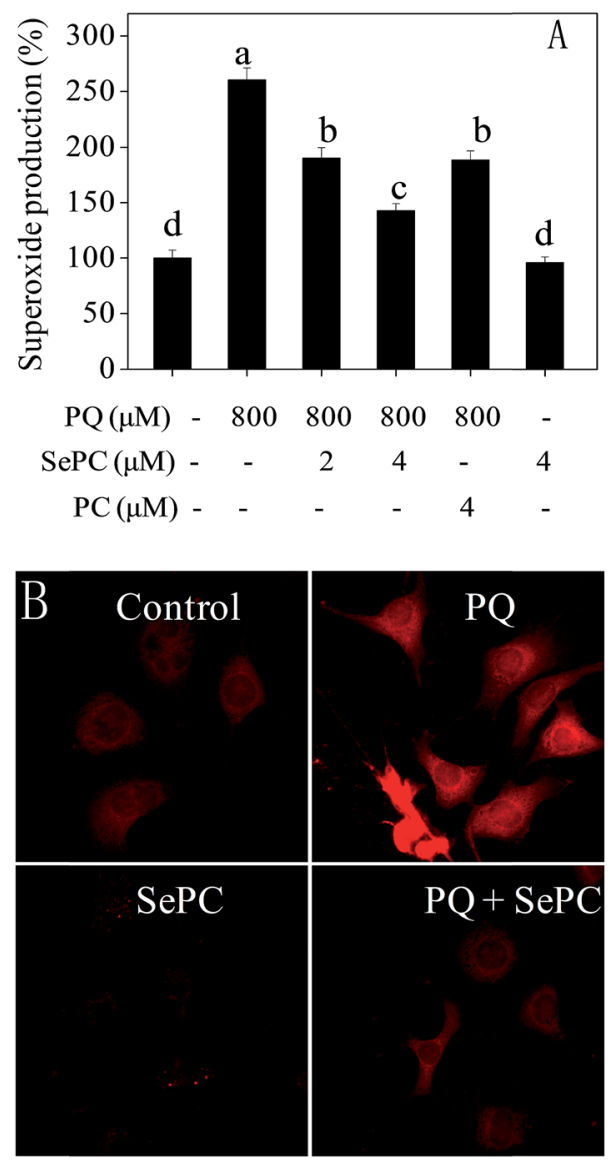

Fig. 5 (A) Selenium-phycocyanin (Se-PC) blocks paraquat (PQ) induced superoxide overproduction in HK-2 cells. (B) Se-PC reduces $P Q$-induced intracellular superoxide anion level examined using DHE fluorescent probe.
Therefore, intracellular superoxide anion level was examined by DHE fluorescent probe.

As shown in Fig. 5, PQ caused significant increase of superoxide anion level in HK-2 cells. For instance, treatment of cells with $800 \mu \mathrm{M}$ PQ notably promoted the superoxide anion level to $260.4 \%$. However, co-treatment of the HK-2 cells with 4 $\mu \mathrm{M}$ Se-PC significantly prevented the superoxide anion rate to $142.6 \%$. The protective effect of PC at $4 \mu \mathrm{M}$ is similar to that of Se-PC at $2 \mu \mathrm{M}$. However, the effect of Se-PC at $4 \mu \mathrm{M}$ was the strongest achieved. Moreover, no significant change in superoxide anion level was detected after treatment with $4 \mu \mathrm{M} \mathrm{Se}-\mathrm{PC}$ alone. Fluorescent images detected by microscope further confirmed the protective effects of Se-PC, as convinced by weaken red fluorescence (Fig. 5B). The results indicate that Se$\mathrm{PC}$ prevents $\mathrm{PQ}$-induced superoxide overproduction in $\mathrm{HK}-2$ cells, and Se incorporation into PC enhances its antioxidant activity.

In summary, a fast liquid chromatographic method for separation and purification of Se-PC from Se-enriched Nostoc sp. has been established. The purified Se-PC drastically prevented PQ-caused oxidative damage and nephrotoxicity in $\mathrm{HK}-2$ proximal tubular cells. Mechanism investigation revealed that Se-PC blocked PQ-induced cell apoptosis through restraining the overproduction of superoxide. In conclusion, we suggest that Se-PC is a promising Se species for the advanced treatment of oxidative stress-mediated renal injury.

\section{Conflicts of interest}

There are no conflicts to declare.

\section{Acknowledgements}

This work was supported by the Natural Science Foundation of China (31000246), the Major State Basic Research Development Program (973) of China (No. 2011CB100400-G), YangFan Innovative \& Entepreneurial Research Team Project (201312H05), Guangdong Special Support Program and Guangdong Frontier Key Technological Innovation Special Funds (2014B050505012), the Science and Technology Planning Project of Guangdong Province (2015A020209152, 2016A030303050) and Fundamental Research Funds for the Central Universities.

\section{References}

1 R. J. Dinis-Oliveira, J. A. Duarte, A. Sánchez-Navarro, F. Remião, M. L. Bastos and F. Carvalho, Crit. Rev. Toxicol., 2008, 38, 13-71.

2 J. Chen, T. Zeng, Y. Bi, Z. Zhong, K. Xie and X. Zhao, Inhalation Toxicol., 2013, 25, 9-16.

3 F. Maya, J. M. Estela and V. Cerdà, Talanta, 2011, 85, 588595.

4 M. R. Juchau, A. G. Fantel, C. Harris and B. K. Beyer, Environ. Health Perspect., 1986, 60, 131-136.

5 Z. E. Suntres, Toxicology, 2002, 180, 65-77.

6 E. A. Awadalla, Exp. Toxicol. Pathol., 2012, 64, 431-434.

7 G. W. Burton, Proc. Nutr. Soc., 1994, 53, 251-262. 
8 R. J. Reiter, Prog. Neurobiol., 1998, 56, 359-384.

9 N. K. Sharma, S. P. Tiwari, K. Tripathi and A. K. Rai, J. Appl. Phycol., 2011, 23, 1059-1081.

10 C. Halfmann, L. Gu and R. Zhou, Green Chem., 2014, 16, 3175-3185.

11 D. Han, Y. Bi and Z. Hu, Handbook of microalgal culture: biotechnology and applied phycology, ed. A. Richmond, Oxford: Blackwell Science, 2004, pp. 304-311.

12 A. Ramos, F. Acién, J. M. Fernández-Sevilla, C. V. González and R. Bermejo, J. Chem. Technol. Biotechnol., 2010, 85, 783-792.

13 M. C. Santiago-Santos, T. Ponce-Noyola, R. Olvera-Ramírez, J. Ortega-López and R. O. Cañizares-Villanueva, Process Biochem., 2004, 39, 2047-2052.

14 A. A. Tchernov, K. M. Minkova and N. B. Houbavenska, J. Biotechnol., 1999, 69, 69-73.

15 Y. Sun, J. Zhang, Y. Yan, M. Chi, W. Chen, P. Sun and S. Qin, Environ. Toxicol. Pharmacol., 2011, 32, 168-174.

16 R. Kaur and H. S. Sandhu, Environ. Toxicol. Pharmacol., 2008, 26, 45-48.

17 H. Zhang, T. Chen, J. Jiang, Y. S. Wong, F. Yang and W. Zheng, J. Agric. Food Chem., 2011, 59, 8683-8690.

18 Z. Huang, B. J. Guo, R. N. S. Wong and Y. Jiang, Food Chem., 2007, 100, 1137-1143.

19 J. Riss, K. Décordé, T. Sutra, M. Delage, J. C. Baccou, N. Jouy, J. P. Brune, H. Oréal, J. P. Cristol and J. M. Rouanet, J. Agric. Food Chem., 2007, 55, 7962-7967.

20 T. F. Chen, Y. S. Wong and W. Zheng, Phytochemistry, 2006, 67, 2424-2430.

21 T. F. Chen and Y. S. Wong, J. Agric. Food Chem., 2008, 56, 4352-4358.
22 C. Fan, J. Chen, Y. Wang, Y. S. Wong, Y. Zhang, W. Zheng, W. Cao and T. Chen, Free Radical Biol. Med., 2013, 65, 305316.

23 T. F. Chen and Y. S. Wong, Biomed. Pharmacother., 2009, 63, 105-113.

24 B. Soni, B. Kalavadia, U. Trivedi and D. Madamwar, Process Biochem., 2006, 41, 2017-2023.

25 B. Soni, U. Trivedi and D. Madamwar, Bioresour. Technol., 2008, 99, 188-194.

26 S. G. Yan, L. P. Zhu, H. N. Su, X. Y. Zhang, X. L. Chen, B. C. Zhou and Y. Z. Zhang, J. Appl. Phycol., 2011, 23, 1-6.

27 C. Fan, J. Jiang, X. Yin, K. H. Wong, W. Zheng and T. Chen, Food Chem., 2012, 134, 253-261.

28 T. F. Chen and Y. S. Wong, J. Agric. Food Chem., 2008, 56, 10574-10581.

29 S. J. Riedl and Y. Shi, Nat. Rev. Mol. Cell Biol., 2004, 5, 897907.

30 K. S. Putt, G. W. Chen, J. M. Pearson, J. S. Sandhorst, M. S. Hoagland, J. T. Kwon, S. K. Hwang, H. Jin, M. I. Churchwell and M. H. Cho, Nat. Chem. Biol., 2006, 2, 543-550.

31 R. Cetin, E. Devrim, B. Kilicoglu, A. Avci, O. Candir and I. Durak, J. Appl. Toxicol., 2006, 26, 42-46.

32 Y. Li, X. Li, Y. S. Wong, T. Chen, H. Zhang, C. Liu and W. Zheng, Biomaterials, 2011, 32, 9068-9076.

33 L. Ferder, F. Inserra and M. Martinez-Maldonado, Curr. Hypertens. Rep., 2006, 8, 191-198.

34 M. J. Sung, D. H. Kim, Y. J. Jung, K. P. Kang, A. S. Lee, S. Lee, W. Kim, M. Davaatseren, J. T. Hwang and H. J. Kim, Kidney Int., 2008, 74, 1538-1547. 